\title{
sciendo
}

DOI: 10.2478/orga-2021-0019

\section{Are we Ready to Use Microchip Implants? An International Cross- sectional Study}

\author{
Anja ŽNIDARŠIČ ${ }^{1}$, Alenka BAGGIA ${ }^{1}$, Antonín PAVLíčEK ${ }^{2}$, \\ Jakub FISCHER ${ }^{2}$, Maciej ROSTAŃSKI ${ }^{3}$, Borut WERBER ${ }^{1}$ \\ ${ }^{1}$ Faculty of Organizational Sciences, University of Maribor, Kranj, Slovenia, anja.znidarsic@um.si (AZ), \\ alenka.baggia@um.si (AB), borut.werber@um.si (BW) (corresponding author) \\ ${ }^{2}$ Faculty of Informatics and Statistics, Prague University of Economics and Business, Prague, Czech Republic, \\ antonin.pavlicek@vse.cz (AP), fischerj@vse.cz (JF) \\ ${ }^{3}$ Faculty of Computer Science, Academy of Business in Dabrowa Gornicza, Dąbrowa Górnicza, Poland, \\ mrostanski@gmail.com (MR)
}

\begin{abstract}
Background and purpose: Despite their clear relevance to human life, microchip implants are still widely viewed as negative, threatening our privacy and raising growing concerns about our health. This paper aims to investigate the important factors influencing people's perception of microchip implants and their willingness to use them for different purposes.

Methodology: The cross-sectional study was conducted in three European countries and the data were analysed using the group Structural Equation Modeling approach. Only complete answers to the online survey questionnaire items were used representing a convenience sample of 804 respondents.

Results: The results show that perceived ease of use, usefulness and perceived trust are significant predictors of intention to use microchip implants. Perceived trust is influenced by privacy and technology safety. Concerns about painful procedures and other health concerns reduce the perceived usefulness of microchip implants. Apart from the predictor health concerns, the results were similar in all countries.

Conclusion: Based on the presented results, researchers interested in investigating the actual use of microchip implants can establish a solid foundation for their research. The results may assist policy makers in developing the regulations to ensure the safe use of microchip implants and allow for a higher level of security. As a follow-up, investigation of changes in the acceptance of microchip implants following the threat of a global pandemic is proposed.
\end{abstract}

Keywords: Microchip implant, Near field communication, Behavioural intentions, Structural equation model, Technology acceptance model

\section{Introduction}

Changes in industry opened the door to a variety of emerging technologies, such as wearable Internet, cooperating to coordinating machines (Internet of Things), technologies implanted in the human body, and others. These innovative technologies are capable of helping in unpredictable critical situations that occur anywhere in the world, for example digital tracking of patients and identi- fying their contacts.

Another successful example are mobile or wearable devices based on Radio Frequency Identification (RFID) that use electromagnetic fields to transmit data. Although these devices are revolutionizing healthcare and medicine (Virkki et al., 2017), they are still vulnerable to loss and theft. RFID microchip implants (MI) do not have these shortcomings. MIs are widely used for healthcare applications such as monitoring (Basham, 2014), enhancement medical devices, and other therapeutic purposes (K. Michael

Received: 24th May 2021; revised: 23th August 2021; accepted: 23th September 2021 
\& Michael, 2013). In addition to healthcare applications, MIs have also been shown to be effective in minimizing errors and personally identifiable medical information (Mohamed, 2020). These novel approaches could make a positive contribution by enhancing the security and safety of people in extreme situations (Sarwar et al., 2019). On the other hand, MI could pose some health risks (e.g., rejection, allergic reaction) or threats to privacy and security (Rodriguez, 2019).

The research on MI adoption found in the literature focuses on either students (Smith, 2008), specific age groups (Achille et al., 2012), small business owners (K. Michael et al., 2017), or even a population with various disabilities (Mohamed, 2020). In this paper, we aim to identify and explore the factors that influence the population's intentions to use MIs. The MI under consideration is a passive NFC RFID device which does not require power supply and can be read only from a short distance. To the best of our knowledge, research on the adoption of MIs from the users' perspective has not been performed on a wider basis and reported in the literature. Based on a prior pilot study (Werber et al., 2018), an international cross-sectional study was conducted in four European countries.

The main contribution of this paper is a model of the factors that influence end-user's behavioural intention to use MIs, followed by the analysis of the relationships between the constructs of the research model and the analysis of national differences in behavioural intention to use MIs.

\section{Literature review}

The general use of RFID has been researched for almost two decades. In recent years, we have witnessed a breakthrough in the use of RFID in healthcare and medicine (Virkki et al., 2017). Whereas active RFID tags require a power source, passive tags draw their energy from the radio wave of an RFID reader, so no power is needed (Gaffney \& Gopini, 2020). One of the applications of RFID technology is Near Field Communication (NFC) microchips that can be implanted in the human body. These MIs come inside a glass tube and can be read only from a short distance.

MIs have also been used in healthcare for prosthetic, monitoring, and enhancement medical devices, to combat diseases such as epilepsy, Parkinson's disease and severe depression (K. Michael \& Michael, 2013), and to impair cancer cells (Lai et al., 2016). The use of MIs helps to minimize errors in the collection of important medical information (Mohamed, 2020). In addition to use in health care, there are reports of actual cases where MIs have been used to support intervention in natural disasters (Sarwar et al., 2019).

\subsection{Technology acceptance}

Various methods have been used to research the acceptance of RFID technology and MIs in particular. The Technology Acceptance Model (TAM) is widely used to determine the level of technology acceptance. TAM model anticipates two basic factors that influence the behavioural intention to use technology: perceived usefulness and perceived ease of use (Davis, 1989). Researchers have used other approaches to determine the intention for use new technologies. Katz \& Rice (2009) defined their own scales to determine the potential for RFID use in healthcare, whereas some authors also identified age as an important predictor of technology use (Gauttier, 2019).

\subsection{Microchip implant acceptance}

Due to their specifics, the willingness to use MIs depends not only on perceived usefulness and perceived ease of use, but also on other factors mainly related to health and privacy issues. When implanting a foreign object in the human body, health is always the first consideration. Despite the increasing popularity of MI, the potential health risks have not been adequately researched to ensure the safety of its use. Various problems have been cited in the literature, ranging from the risks of movement in the body, possible effect on emotional behaviour, allergies, effect on the nervous system, and pain during the insertion of the MI (Fram et al., 2020). According to Albrecht (2010), MIs could potentially lead to malignancies, whereas Lai et al. (2016) have found the possibility of treating cancer cells with MIs. However, most of this research is based on microchips for animals, while there is limited evidence on the safety of MI in humans (Fram et al., 2020).

The first specific study of RFID adoption in healthcare from an end-user perspective found that physical placement (without actual insertion into the body) did not appear to raise public concern, with the exception of a small minority (Katz \& Rice, 2009). Public interest in RFID was strongest for emergency intervention services. Research on the acceptance of MIs showed that they were treated positively (Smith, 2008), and the acceptance of MIs for life-saving purposes was highest (Rotter et al., 2008).

In addition, studies have found that the willingness to adopt MIs is slowly increasing (Perakslis et al., 2014), although the perception of MIs as secure technology varies according by country of residence and generational factors (Perakslis \& Michael, 2012). Carr (2020) believes that MIs can be a solution to reduce contacts and risks after pandemic outbreaks. MIs have been used for various non-therapeutic purposes, initially for personal interest only (K. Michael \& Michael, 2013), but more recently in the workplace, for example to access a secured workstation (Fram et al., 2020). According to K. Michael et al. 
(2017), there are numerous reasons for rejecting MIs for employee identification, where data protection and security reasons certainly cannot be ignored (Rodriguez, 2019). Chipping employees in the workplace raises even more ethical issues and challenges (Gauttier, 2019). The situation during pandemics has shown, how quickly privacy rights can disappear when confronted with health and safety concerns and therefore it is crucial to draft the employee microchipping legislation (Turner, 2020).

\subsection{Structural equation modelling}

Structural equation modelling approach is mainly used to test the hypotheses in the technology acceptance model (Beaujean, 2014). The minimum sample size for performing SEM has been discussed several times. Proposals range from 150 to 400 when there are three or more measured items per latent variable (Hair et al., 2019) or 250 to avoid rejection of the model due to the combination of rules for fit indices (Hu \& Bentler, 1999).

Schumacker \& Lomax (2010) propose the analysis performed according to the standard two-stage approach at SEM, the first step being the validation of the measurement model. The Confirmatory Factor Analysis (CFA) is performed to determine how well the measured items reflect the theoretical latent variables and to examine the construct validity of the measurement model, which is examined through convergent validity and discriminant validity. When examining convergent validity, one needs to examine that the estimates of standardized factor loadings do not exceed 0.5 (or even 0.7), Composite Reliability (CR) for each latent variable exceeds 0.7 , and Average Variance Extracted (AVE) for each latent variable exceeds 0.5 (Koufteros, 1999).

In a second step, SEM is used to test the structural relationships between the latent variables. The unstandardized $\mathrm{B}$ and standardized path coefficients $\beta$ (relationships between the latent variables), $z$-values (ratio of $\beta$ to its standard error), and the significance level are calculated. For each endogenous latent variable, a coefficient of determination $\left(\mathrm{R}^{\wedge} 2\right)$ is calculated, representing the percentage of the explained variance of the variable by the set of its predictors.

The overall fit of the measurement and structural model are assessed based on a set of fit indices:

- The value of the comparative fit index (CFI) should be at least 0.9 to indicate adequate model fit (Koufteros, 1999).

- The root mean square error of approximation (RMSEA) value should be below 0.06 (Teo \& Zhou, 2014), or between 0.06 and 0.08 to be interpreted as mediocre (MacCallum et al., 1996).

- The standardised root mean square residual (SRMR) should be less than 0.05 , however values as high as 0.08 are deemed acceptable (Hu \&
Bentler, 1999).

- Some goodness-of-fit (GFI) indices are affected by the complexity of the model (e.g., CFI, but not RMSEA) (Cheung \& Rensvold, 2002). Therefore, generally accepted criterion (e.g., CFI $=0.90$ ) in complex models should be judged with caution.

Multigroup Confirmatory Factor Analysis (MG-CFA) and multigroup Structural Equation Modelling (MG-SEM) is then used to complement the general two-step procedure when we have multiple groups. Using MG-CFA and MGSEM we can assess the measurement invariance (MInv), concerning the comparison of the same measurement model in different groups, and compare the effects or constructs' means across groups, which concerns the analysis of the moderating role of a categorical variable that forms groups in a specified SEM (Miceli \& Brabaranelli, 2016).

Before making meaningful comparisons of survey results across groups, researchers should ensure that respondents from different groups have ascribed similar meaning to survey items (Cheung \& Lau, 2011). MInv assesses the psychometric equivalence of a construct across groups or over time (Putnick \& Bornstein, 2016), while measurement noninvariance suggests that a construct has a different structure and/or meaning to different groups. MInv is usually tested using configural invariance, weak invariance, and strong invariance, sometimes these are followed by strict invariance (Beaujean, 2014).

The configural invariance tests whether the model configuration (all constructs have the same pattern of free and fixed parameters) is the same among all groups in a multigroup context (Putnick \& Bornstein, 2016). For weak invariance, the item loadings must be the same across groups, for strong invariance the intercepts of indicators must be the same across groups, while for strict invariance also error variances must be constrained to be equal across groups.

The results for each invariance test are explained by the change of several alternative fit indices (AFI) since $\chi^{\wedge} 2$ tends to be oversensitive to small, unimportant deviations from a perfect model in large samples (Chen, 2007). Change in CFI $(\triangle \mathrm{CFI})$, SRMR ( $\triangle \mathrm{SRMR})$, and RMSEA ( $\triangle$ RMSEA) were used to assess model fit. Cheung \& Rensvold (2002) proposed the use of a criterion of -0.01 change in CFI of two nested models. Whereas Chen (2007) suggested that a criterion of a -0.01 for $\triangle \mathrm{CFI}$ is paired with $\triangle$ RMSEA of 0.015 and SRMR of 0.030 (for metric invariance) or 0.015 (for scalar or residual invariance).

The rules of thumb for AFI and $\triangle$ AFI might not generalize to the wide range of SEMs encountered in practice, models with only negligible mis-specifications should not be rejected, and researchers should not rely on a single rule-of-thumb cut-off for any $(\Delta)$ AFI (Jorgensen et al., 2018). Traditionally, configural invariance is assessed by evaluating the overall fit of the configural model, whereas (Jorgensen et al., 2018) proposed a permutation test, espe- 
cially when evaluating configural invariance with small to moderate sample sizes. As pointed out by Jorgensen et al. (2018) configural models frequently do not fit the data perfectly, but the use of the permutation test of configural invariance can prevent inflated type I errors when the model fits only approximately well. The idea of the permutation test is that the variable of group membership is randomly shuffled (several times) and the model is fitted to that data. In the permutation test, the proportion of the statistics (e.g. $\chi^{\wedge} 2$, CFI, RMSEA) that are more extreme than the observed statistics (of the original model), is calculated. This is a one-tailed p-value that approximates the probability of obtaining statistics under investigation (e.g. $\chi^{\wedge} 2$ ), as poor as the observed one, if the invariance across all groups holds true. If $\mathrm{p}<\alpha, \mathrm{H} 0$ has to be rejected. The permutation test could be applied for both badness of fit measures (e.g. $\chi^{\wedge} 2$, RMSEA,...) or goodness of fit indices (e.g. CFI) (see e.g. Jorgensen et al. (2018) for further information).

\section{Methods}

On the basis of previous studies (e.g. M. G. Michael \& Michael, 2010; Perakslis et al., 2014), we constructed a model of factors influencing the behavioural intentions to use MIs based on TAM, as shown in Figure 1. The extended model based on TAM adopts the components of TAM: Perceived Ease of Use (PEU), Perceived Usefulness (PU), and Behavioural Intention to Use (BIU). We added constructs of personal factors to the basic model of TAM: Perceived Trust (PT), Privacy Right (PR), Privacy Threat (PTh) and Health Concerns (HC). Three predictor variables have been added to the model: Age, Technology Safety, and Painful Procedure.

The items of basic TAM constructs were defined according to previous research:

- Perceived Ease of Use (PEU): Items availability, and multifunctionality were adopted from the original TAM model (Davis, 1989), whereas the items on the option to be lost or stolen were included on the basis of the pilot study (Werber et al., 2018).

- Perceived Usefulness (PU): In addition to five items adopted from (Katz \& Rice, 2009), the items on organ donation information and saving lives under different conditions were added based on the pilot study (Werber et al., 2018).

- Behavioural Intention to Use (BIU): Based on the pilot study, items considered intention to use for healthcare purposes, for identification purposes, for shopping and payment, and for everyday use at home. The intention to use in case GPS positioning and tracking was not possible was added. Age was included as a predictor variable to BIU construct based on previous research on the influence of age on the adoption of new technologies
(Gauttier, 2019).

- Additional constructs of personal factors were constructed on the basis of earlier research as follows:

- Health Concerns (HC): HC concerns refer to possible health risks of MI derived from previous research (e.g. Albrecht, 2010). The variable Painful Procedure (PP) was adopted based on the basis of claims that pain or damage is associated with the insertion of MI (M. G. Michael \& Michael, 2010).

- Perceived Trust (PT): Items concerning the perceived trust that the state and other institutions will ensure security have been derived from (Smith, 2008). The variable Technology Safety (TS) associated with PT has been adopted as a predictor variable in PT construct from (Perakslis et al., 2014).

- $\quad$ Privacy Right (PR): Items concerning the level of privacy were adopted from Lockton \& Rosenberg (2005).

- Privacy Threat (PTh): The construct was included in the model on the basis of previous research (Bansal et al., 2015), assuming that it has a negative impact on the perceived right to privacy.

Items of HC, PP, PT, PR, PTh, TS and PEU, were measured on a 5-point scale of agreement ("strongly disagree" to "strongly agree"), whereas the items of PU were measured on a 5-point scale of acceptability ("very bad idea" to "very good idea"). Five items on BIU were measured with yes/no options.

To study the relationships among our constructs, nine hypotheses presented in Table 1 were postulated. In addition, positive or negative impacts between constructs are depicted.

The relationships among constructs, together with the type of the relationship (positive or negative), are presented in Figure 1 as a proposed MI acceptance model.

To test the hypotheses of the proposed structural model, we updated the pre-developed questionnaire (Werber et al., 2018). Two scales on Privacy Right and Privacy Threat (Katz \& Rice, 2009) and an item on Technology safety (Perakslis et al., 2014) were added.

\subsection{Data collection}

The convenience sampling approach was utilized in MIs acceptance research. Respondents were invited to participate in an online survey through various channels, ranging from the researcher's social networks to media posts. The survey was conducted in 2016 and 2017 in four countries: Slovenia, the Czech Republic, Poland, and Croatia. The introduction to the survey, included the description that the research was about passive NFC RFID microchip implants that do not require power supply and 
Table 1: Research hypotheses and their relationships

\begin{tabular}{|l|l|l|}
\hline Research hypotheses & Relationship & Type \\
\hline H1: Privacy threat will have a significant positive effect on privacy right & PTh $\rightarrow$ PR & Positive \\
\hline H2: Privacy right will have a significant negative effect on perceived trust & PR $\rightarrow$ PT & Negative \\
\hline H3: Technology safety will have a significant positive effect on perceived trust & TS $\rightarrow$ PT & Positive \\
\hline H4: Painful procedure will have a significant positive effect on health concerns & PP $\rightarrow$ HC & Positive \\
\hline H5: Health concerns will have a significant negative effect on perceived usefulness & HC $\rightarrow$ PU & Negative \\
\hline H6a: Perceived ease of use will have a significant positive effect on perceived usefulness & PEU $\rightarrow$ PU & Positive \\
\hline H6b: Perceived ease of use will have a significant positive effect on behavioural intention to & PEU $\rightarrow$ BIU & Positive \\
\hline H7a: Perceived Trust will have a significant positive effect on perceived usefulness & PT $\rightarrow$ PU & Positive \\
\hline H7b: Perceived Trust will have a significant positive effect on behavioural intention to use & PT $\rightarrow$ BIU & Positive \\
\hline H8: Perceived usefulness will have a significant positive effect on behavioural intention to & PU $\rightarrow$ BIU & Positive \\
\hline H9: Age will have a significant negative effect on behavioural intention to use & Age $\rightarrow$ BIU & Negative \\
\hline
\end{tabular}

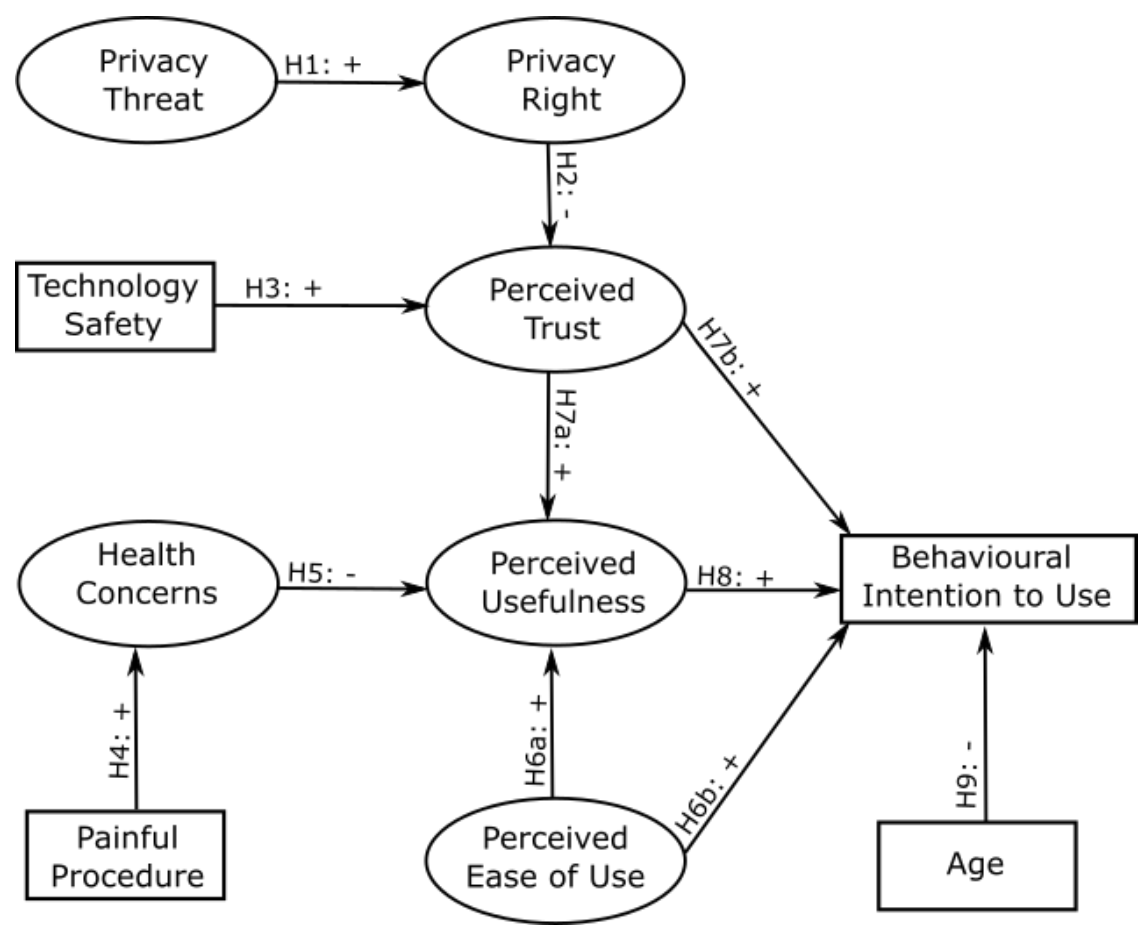

Figure 1: The proposed acceptance model for behavioural intentions to use microchip implant 
can be read only from a short distance. Possible uses of MIs were also listed.

The questionnaire was distributed to a convenience sample of the general population. Only complete answers to the questionnaire items were used, namely $250(31.1 \%)$ from Slovenia, 339 (42.2\%) from the Czech Republic, and 215 (26.7\%) from Poland. The Croatian subsample (146) was excluded from the analyses due to the minimal sample size requirements for structural equation modeling (SEM).

\subsection{Statistical methods}

The measurement model shown in Figure 1 describes the relationships between the observed measured items and the unobserved latent variables. The data obtained from the survey were analysed using the SEM approach.

The analysis was performed according to the standard two-stage approach at SEM (Schumacker \& Lomax, 2010), the first step being the validation of the measurement model, whereas in the second step, structural relationships between latent variables were tested. The overall fit of the measurement and structural model were assessed based on a set of fit indices. MG-CFA and MG-SEM were used to complement the general two-step procedure due to the multiple groups representing samples from three countries.

All analyses, CFA, MInv, and SEM, were performed with the R-package lavaan (Rosseel, 2014) and semTools (Jorgensen et al., 2020). In the following section, the results are presented according to the described analysis procedure.

\section{Results}

In this section the results of 804 responses with complete answers to the items included in the research model ( $88.16 \%$ of 912 responses) are presented. The sample consists of $51.56 \%$ women and $48.44 \%$ men, detailed distribution according to countries is presented in Table 2.

The majority of respondents are employed $(67.75 \%)$ or students $(20.88 \%)$. The status of respondents according to countries is presented in Table 3 .

The mean age of the respondents is 37.5 years with standard deviation 13.91 years. The age distribution according to countries is presented in Table 4.

Table 2: Gender distribution according to country

\begin{tabular}{|lcl|}
\hline & Men & Women \\
\hline Slovenia & $40.96 \%$ & $59.04 \%$ \\
the Czech Republic & $47.49 \%$ & $52.51 \%$ \\
Poland & $58.69 \%$ & $41.31 \%$ \\
\hline
\end{tabular}

Table 3: Status of respondents according to country

\begin{tabular}{|lcccc|}
\hline & Student & Employed & Unemployed & Retired \\
\hline Slovenia & $33.73 \%$ & $53.82 \%$ & $5.62 \%$ & $6.83 \%$ \\
the Czech Republic & $20.48 \%$ & $68.25 \%$ & $3.26 \%$ & $8.01 \%$ \\
Poland & $6.54 \%$ & $83.18 \%$ & $5.14 \%$ & $5.14 \%$ \\
\hline
\end{tabular}

Table 4: Descriptive statistics (means (M) and standard deviations (SD)) for age of respondents according to country

\begin{tabular}{|lcc|}
\hline & M & SD \\
\hline Slovenia & 35.7 & 11.8 \\
the Czech Republic & 38.0 & 14.2 \\
Poland & 38.7 & 11.8 \\
\hline
\end{tabular}




\subsection{Descriptive statistics of the questionnaire items}

The percentages of respondents who are willing to insert a MI for different usages are shown in Table 5. The highest percentage of the respondents $(47.76 \%)$ would insert an MI for health care purposes and the lowest percentage of the respondents (20.65\%) would have MI for shopping and payment. The variable "number of MI uses" was calculated as the sum of five dichotomous variables on different MI uses and its mean value was 1.53 and SD $=1.85$ (Table 6 ).

Descriptive statistics for 25 continuous variables included in the research model are presented in Table 6. On average, the highest agreement among respondents was in the case of PR construct for the variables discussing the right to control your information $(\mathrm{M}=4.50, \mathrm{SD}=0.73)$, and that no one should be able to collect or disclose your personal information without your consent ( $\mathrm{M}=4.46, \mathrm{SD}$ $=0.83)$. On average, the largest disagreement is obtained for the statement about the security and protection of human rights $(\mathrm{M}=2.53, \mathrm{SD}=1.23)$.

\subsection{Measurement model evaluation}

Construct validity aims to determine how well a set of measured items reflects the theoretical latent variable they are designed to measure. Construct validity is examined with the evaluation of convergent validity and discriminant validity.

\section{Convergent validity}

First, the initial overall measurement model (M1), disregarding the countries was evaluated. The results of measurement model development and the fit indices are presented in Table 7 . The item PEU3 $(\lambda=0.441)$ was removed from the model, due to its standard loading below 0.5 .

Standardized factor loadings for items in the (final) overall model (M2) exceed a threshold of 0.5 for convergent validity. In addition, 86\% (18) of them exceed even a stricter threshold of 0.7 .

The AVE for six constructs exceeds a threshold of 0.5 for convergent validity (Table 8). The AVE for PEU is slightly below $0.5(\mathrm{AVE}=0.47)$, but its $\mathrm{CR}$ is higher than $0.6(\mathrm{CR}=0.73)$ the convergent validity of the construct is still adequate (Fornell \& Larcker, 1981). The obtained results prove the convergent validity for the set of latent variables and corresponding items in the measurement model, therefore all included items are significantly related to the specified latent variable.

\section{Discriminant validity}

The discriminant validity of the M2 (overall) measurement model was examined through the comparison of the square root of AVE of each latent variable to the correlations between the latent variables (Table 8). The correlations among the constructs (and three measured variables included in the structural model) are given in the right panel of Table 8, where the diagonal elements correspond to the values of the square root of AVE. The values of the square root of AVE for each construct surpass the corresponding correlations between constructs. Therefore, discriminant validity can be inferred for all latent variables.

Internal consistency of the questionnaire was assessed to determine the extent to which the measured items within the construct were related to each other. Cronbach's alpha coefficients (Table 8) for six constructs ranged from 0.79 to 0.92 indicating high internal reliability (Hair et al.,

Table 5: Willingness to insert microchip implant $(N=804)$

\begin{tabular}{|l|c|}
\hline Would you insert MI: & PPR $^{\mathrm{a}}$ \\
\hline $\begin{array}{l}\text {...for health care purposes (identification, storage of medical data, information on organ donations, } \\
\text { etc.)? }\end{array}$ & $47.76 \%$ \\
\hline ...for identification purposes (ID card, passport, driving license, etc.)? & $31.22 \%$ \\
\hline ...for shopping and payment purposes (debit cards, credit cards, profit cards, etc.)? & $20.65 \%$ \\
\hline ...for everyday use at home (unlocking of house or apartment, car, computer, mobile phone, etc.)? & $22.76 \%$ \\
\hline ...if you had been assured that GPS tracking and positioning would not be possible? & $30.60 \%$ \\
\hline
\end{tabular}

aPPR - Percentages of positive responses 
Table 6: Descriptive statistics with means (M) and standard deviations (SD) of items for model constructs $(N=804)$

\begin{tabular}{|c|c|c|c|}
\hline Construct & Questionnaire item & M & SD \\
\hline \multirow{2}{*}{ 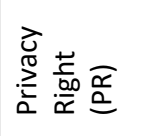 } & $\begin{array}{l}\text { No one should be able to gather or disclose your personal information without your consent. } \\
\text { (PR1) }\end{array}$ & 4.46 & 0.83 \\
\hline & People should have the right to control their personal information. (PR2) & 4.50 & 0.73 \\
\hline \multirow{3}{*}{ 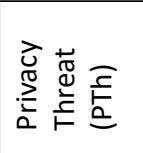 } & Organizations and agencies ask you for too much personal information. (PTh1) & 3.93 & 0.94 \\
\hline & The present use of computers is an actual threat to personal privacy in the country. (PTh2) & 3.69 & 1.02 \\
\hline & I am concerned about threats to my privacy in the country today. (PTh3) & 3.49 & 1.11 \\
\hline 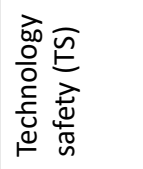 & Mls technology is safe enough to be used in humans. (TS1) & 2.66 & 1.01 \\
\hline \multirow{4}{*}{ 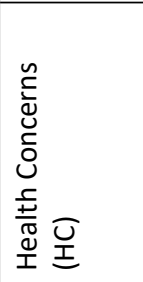 } & Mls can be threatening to my health because of the possibility of movement in my body. (HC1) & 2.94 & 1.08 \\
\hline & Mls may affect my emotional behaviour (control of human behaviour, etc.). (HC2) & 2.70 & 1.18 \\
\hline & Mls can be threatening to my health because of possible allergies. (HC3) & 3.29 & 1.09 \\
\hline & MIs can be threatening to my health because of their impact on the nervous system. (HC4) & 3.06 & 1.11 \\
\hline 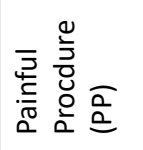 & Implanting MI is a painful procedure. & 2.84 & 1.02 \\
\hline \multirow{3}{*}{ 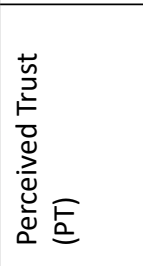 } & $\begin{array}{l}\text { The state will ensure the security and the protection of human rights (security of identity } \\
\text { documents, passport, identity theft, tracking via GPS, no records should be archived without } \\
\text { the consent of the person observed). (PT1) }\end{array}$ & 2.53 & 1.23 \\
\hline & Banks will provide security (payment, discretion of operation, transactions, etc.). (PT2) & 2.68 & 1.22 \\
\hline & $\begin{array}{l}\text { The healthcare system will provide security (personal data, medical data, information on treat- } \\
\text { ments, organ donation, etc.). (PT3) }\end{array}$ & 3.05 & 1.26 \\
\hline \multirow{7}{*}{ 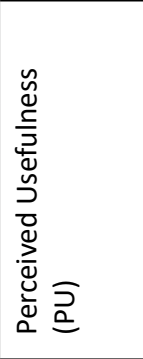 } & Mls could be used for & & \\
\hline & - monitoring the health of the user. (PU1) & 3.71 & 1.04 \\
\hline & - warning about potential health problems or complications. (PU2) & 3.80 & 1.02 \\
\hline & - storing a user's medical info to be used in an emergency. (PU3) & 3.80 & 1.02 \\
\hline & - personalized health info. (PU4) & 3.39 & 1.15 \\
\hline & - storing information about organ donation. (PU5) & 3.43 & 1.14 \\
\hline & - saving life (e.g. unconsciousness, cardiac pacemaker, insulin dispenser). (PU6) & 3.85 & 1.00 \\
\hline \multirow{4}{*}{ 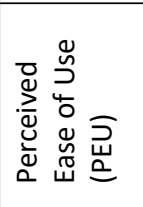 } & MIs are always available. (PEU1) & 3.55 & 0.99 \\
\hline & Mls cannot be lost. (PEU2) & 3.78 & 0.96 \\
\hline & MIs cannot be stolen (high-security protection). (PEU3) & 3.08 & 1.18 \\
\hline & MIs can integrate multiple functions at the same time. (PEU4) & 4.01 & 0.80 \\
\hline 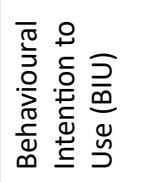 & Number of different subcutaneous microchip uses. & 1.53 & 1.85 \\
\hline
\end{tabular}


Table 7: Results of measurement model development and model fit indices

\begin{tabular}{|l|l|c|l|l|l|}
\hline \multicolumn{1}{|c|}{ Model } & \multicolumn{1}{|c|}{$\chi^{2}$} & $d f$ & $C F I$ & SRMR & $\begin{array}{l}\text { RMSEA } \\
90 \% \mathrm{Cl}\end{array}$ \\
\hline M1 - initial overall model & 1010.560 & 194 & 0.916 & 0.052 & 0.072 \\
\hline M2 - overall model with removed PEU3 & 863.804 & 174 & 0.927 & 0.049 & 0.070 \\
\hline Final model (M2) for each country & 339.061 & 174 & 0.950 & 0.052 & 0.062 \\
\hline MSI -Slovenia & 589.404 & 174 & 0.877 & 0.067 & 0.084 \\
\hline MCZ - Czech Republic & 359.205 & 174 & 0.940 & 0.051 & 0.070 \\
\hline MPO - Poland & & & & \\
\hline
\end{tabular}

Table 8: Cronbach's Alpha, Composite reliability (CR), average variance extracted (AVE), square root of AVE on the diagonal (marked in grey) and correlations among constructs

\begin{tabular}{|c|c|c|c|c|c|c|c|c|c|c|c|c|c|}
\hline \multicolumn{14}{|c|}{ Correlations } \\
\hline & $\begin{array}{l}\text { Cronbach's } \\
\text { Alpha }\end{array}$ & CR & AVE & PR & PTh & TS & PP & $\mathrm{HC}$ & PT & PU & PEU & Age & $\mathrm{BIU}$ \\
\hline PR & 0.858 & 0.862 & 0.758 & 0.871 & & & & & & & & & \\
\hline PTh & 0.793 & 0.797 & 0.568 & 0.464 & 0.754 & & & & & & & & \\
\hline $\mathrm{TS}^{\mathrm{a}}$ & I & I & I & -0.049 & -0.206 & I & & & & & & & \\
\hline $\mathrm{PP}^{\mathrm{a}}$ & I & I & I & -0.014 & 0.032 & -0.154 & I & & & & & & \\
\hline $\mathrm{HC}$ & 0.838 & 0.855 & 0.597 & 0.098 & 0.278 & -0.503 & 0.466 & 0.773 & & & & & \\
\hline PT & 0.877 & 0.877 & 0.706 & -0.111 & -0.274 & 0.384 & -0.004 & -0.310 & 0.840 & & & & \\
\hline PU & 0.921 & 0.921 & 0.660 & 0.030 & -0.152 & 0.394 & -0.090 & -0.391 & 0.577 & 0.813 & & & \\
\hline PEU & 0.614 & 0.727 & 0.474 & 0.175 & -0.056 & 0.276 & -0.155 & -0.315 & 0.406 & 0.509 & 0.689 & & \\
\hline $\mathrm{Age}^{\mathrm{a}}$ & I & I & I & 0.002 & -0.001 & -0.046 & 0.038 & 0.131 & -0.142 & -0.174 & -0.026 & I & \\
\hline$B I U^{a}$ & I & I & / & -0.086 & -0.238 & 0.368 & -0.074 & -0.391 & 0.541 & 0.471 & 0.334 & -0.140 & I \\
\hline
\end{tabular}

${ }^{a}$ Measured variables TS, PP, Age, and BIU are included into the table only to compare square root of AVE of a construct with correlations to other constructs and measured variables. Cronbach's Alpha, CR, and AVE are not applicable for measured variables.

2019). The coefficient for PEU is slightly lower but still acceptable (Cronbach's alpha $=0.61)$.

\section{The overall model fit}

The overall fit of the final measurement model (M2) was assessed based on a set of commonly used fit indices (Table 7). The $\chi^{\wedge} 2$ was 863.81 with 174 degrees of freedom. Both, CFI and SRMR indicate a good model fit $(\mathrm{CFI}=0.927$ SRMR $=0.049)$. RMSEA is equal to 0.070 and the upper bound of RMSEA 90\% confidence interval $(0.066,0.075)$ is lower than 0.08 suggesting a good model fit (MacCallum et al., 1996). According to the set of the calculated fit indices, we conclude that the measurement model fits the sample data well.

We tested whether our final model fits each country's subsample. The model fits all of the subgroups well, with SRMR values from 0.051 to 0.67 , RMSEAs of 0.062 to 0.084 , CFIs of 0.88 to 0.95 (see Table 7). When examined separately, the M2 fits each subgroup well. Therefore, we can proceed with testing measurement invariance across groups.

\subsection{Multiple-group analyses: testing measurement invariance across countries}

The measurement invariance tests are performed using the hierarchical ordering of nested models (Putnick \& Bornstein, 2016) starting with the evaluation of the configural invariance and following by weak, strong, and strict 
invariance. The results of the model fits are shown in Table 9.

\section{Test of configural invariance}

A permutation test, based on 1000 repetitions, revealed no evidence against the null hypothesis of configural invariance using either $\chi^{\wedge} 2(p=0.557)$, CFI $(p=0.721)$, SRMR $(p=0.375)$ or RMSEA $(p=0.557)$ and its $90 \%$ confidence interval $(\mathrm{p}=0.557$ for the lower bound and upper bound as criterion). This indicates that configural invariance is supported.

\section{Test of weak invariance}

To test for weak invariance, the factor loadings were constrained to be equal across groups. Because the weak invariance model (M4) is nested within the baseline configural model (M3), a $\chi^{\wedge} 2$ difference test was performed. Since $\chi^{\wedge} 2$-test of two nested models is oversensitive to small, unimportant deviation from a perfect model in a large sample (Chen, 2007; Cheung \& Rensvold, 2002), we report the differences in alternative fit indices $(\triangle \mathrm{AFI})$. $\triangle$ CFI (-0.002), $\triangle$ REMSA (-0.001, and $\triangle$ SRMR (0.002) between the configural and weak models (Table 9).

\section{Test of strong invariance}

To test for strong invariance, in addition to factor loadings also intercepts were constrained to be equal across groups. The $\triangle \mathrm{AFIs}$ of strong invariance model (M5) according to M4 were as follows: $\triangle$ CFI (0.020), EMSA (0.006), and $\triangle$ SRMR (0.006). Since $\triangle$ CFI is above the prescribed level, there is some evidence that the intercepts are not completely invariant across the three considered groups. When intercept of measured item PT3 was freely estimated accros groups, the partial strong variance (model M5a) was established.

However, there was a significant CFI difference ( $\triangle \mathrm{CFI}$ $=-0.026)$ between the partial strong model and the strict model (M6). These results suggest a greater lack of fit when constraining also error variances to be invariant across groups. Since partial strong measurement invariance was supported, we can proceed to the evaluation of the structural model (Putnick \& Bornstein, 2016).

Table 9: Testing measurement invariance across countries

\begin{tabular}{|c|c|c|c|c|c|c|}
\hline $\begin{array}{c}\text { Model } \\
\text { (Model comparison) }\end{array}$ & $\begin{array}{c}\chi^{2} \\
\left(\Delta \chi^{2}\right)\end{array}$ & $d f$ & $\begin{array}{c}C F I \\
(\triangle C F I)\end{array}$ & $\begin{array}{c}S R M R \\
(\triangle S R M R)\end{array}$ & 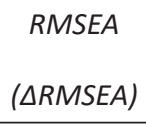 & $\begin{array}{l}\text { RMSEA } \\
90 \% \mathrm{Cl}\end{array}$ \\
\hline M3 - configural invariance & 1287.67 & 522 & 0.922 & 0.056 & 0.074 & $0.069 ; 0.079$ \\
\hline $\begin{array}{c}\text { M4 - weak invariance } \\
\text { (M3) }\end{array}$ & $\begin{array}{r}1330.32 \\
(42.7)\end{array}$ & $\begin{array}{l}552 \\
(30) \\
\end{array}$ & $\begin{array}{c}0.920 \\
(-0.002)\end{array}$ & $\begin{array}{r}0.058 \\
(0.002)\end{array}$ & $\begin{array}{c}0.073 \\
(-0.001)\end{array}$ & $0.068 ; 0.078$ \\
\hline $\begin{array}{c}\text { M5 - strong invariance } \\
\text { (M4) }\end{array}$ & $\begin{array}{l}1563.50 \\
(233.2) \\
\end{array}$ & $\begin{array}{l}582 \\
(30)\end{array}$ & $\begin{array}{c}0.900 \\
(-0.020)\end{array}$ & $\begin{array}{r}0.064 \\
(0.006)\end{array}$ & $\begin{array}{l}0.079 \\
(0.006)\end{array}$ & $0.075 ; 0.084$ \\
\hline $\begin{array}{c}\text { M5a - strong partial invari- } \\
\text { ance } \\
\text { (M3) }\end{array}$ & $\begin{array}{l}1446.28 \\
(116.0)\end{array}$ & $\begin{array}{l}580 \\
(28)\end{array}$ & $\begin{array}{c}0.911 \\
(-0.009)\end{array}$ & $\begin{array}{l}0.062 \\
(0.004)\end{array}$ & $\begin{array}{c}0.075 \\
(0.002)\end{array}$ & $0.070 ; 0.079$ \\
\hline $\begin{array}{l}\text { M6 - strict invariance } \\
\text { (M5a) }\end{array}$ & $\begin{array}{l}1742.68 \\
(296.4)\end{array}$ & $\begin{array}{l}622 \\
(42)\end{array}$ & $\begin{array}{c}0.885 \\
(-0.026)\end{array}$ & $\begin{array}{l}0.064 \\
(0.002)\end{array}$ & $\begin{array}{c}0.082 \\
(0.007)\end{array}$ & $0.077 ; 0.087$ \\
\hline
\end{tabular}

\subsection{Testing structural model}

After assessing the model fit of the overall measurement model and its partial strong invariance, a structural model was evaluated. According to the research model (Figure 1), four measured variables and 11 structural paths were added to the six constructs described in the previous section and in accordance with the proposed hypotheses.
First, the overall model was evaluated.

\section{Examining the overall structural model}

The overall structural model (SM1) fit was good. The following criteria were determined: $\chi^{\wedge} 2=1548.63, \mathrm{df}=264$, $\mathrm{CFI}=0.88$, and RMSEA $=0.078$ (90\% CI; 0.074,0.082). Since the main aim of this research is group comparison, 
the detailed results of the overall model are not presented here.

Although the research hypotheses were supported in the overall model, it is not clear whether these hypotheses hold across different countries. For example, would the impact of health concerns on perceived usefulness remain significant for all three countries? To determine whether the structural relationships are invariant, it is essential to establish a structural model invariance.

\section{Measurement invariance of the structural model}

The fit of the partial strong invariance model (SM1) (Table 10) was good: $\chi^{\wedge} 2=2426.11, \mathrm{df}=822, \mathrm{CFI}=0.86$, and RMSEA $=0.083(90 \%$ CI; 0.079,0.087). The fit of the structural model (SM2), where also structural coefficients were constrained to be equal across groups, was as follows: $\chi^{\wedge} 2=2480.64, \mathrm{df}=872, \mathrm{CFI}=0.85$, and RMSEA $=0.083$ $(90 \% \mathrm{CI} ; 0.079,0.087)$. The $\chi^{\wedge} 2$-test $(\mathrm{p}=0.0001)$ of the two nested models suggests that models SM1 and SM2 are significantly different, meaning that some paths vary across groups.

To determine whether the structural paths are invariant across three groups, the individual structural coefficients were successively restricted to be equal across three groups and nested models were compared. More precisely, model SM1 and a model in which a particular path coefficient of interest was specified as invariant were compared at a time (Table 10). Since we are comparing three groups, such an approach ensures that the $\chi^{\wedge} 2$ difference test has 2 degrees of freedom, whereby any observed $\chi^{\wedge} 2$ differences greater than 5.99 being statistically significant at a $5 \%$ significance level.

Results of model comparisons are presented in Table 10. The following paths were found to be different across groups at $5 \%$ significance level:

- $\quad$ PTh $\rightarrow$ PR (SM1a),

- $\quad \mathrm{PP} \rightarrow \mathrm{HC}$ (SM1d),

- $\quad \mathrm{HC} \rightarrow \mathrm{PU}(\mathrm{SM} 1 \mathrm{e})$,

- $\quad \mathrm{PT} \rightarrow \mathrm{PU}(\mathrm{SM} 1 \mathrm{~h})$.

Those coefficients were freely estimated across groups in the final model (SM3).

\subsection{Results of the final structural model}

The fit of the final model (Table 10) was good: $\chi^{\wedge} 2=2441.77, \mathrm{df}=864, \mathrm{CFI}=0.85$, and $\mathrm{RMSEA}=0.084$ $(90 \%$ CI; 0.079,0.086). Table 11 shows the results for the unstandardized coefficients (B), standardized coefficients $(\beta)$ and corresponding z-values, which reflect the relationships among the latent variables in terms of magnitude and statistical significance. Due to relatively large number of tests, the adjusted p-values using false discovery rate method (Benjamini \& Hochberg, 1995) were calculated. A graphical overview of the (un)confirmed hypotheses is shown in Figure 2. For each endogenous construct the coefficient of determination $\left(\mathrm{R}^{\wedge} 2\right)$ was also calculated (Table 12).

The theory of TAM suggests that there are positive effects of PEU and PU on BIU (in this case H6b and H8). The results confirmed that both hypotheses are confirmed in all three countries at a 5\% significance level and that the structural coefficients do not differ statistically significantly across countries. We found that all constructs together explain $30.6 \%$ of the total variance of BIU in Poland, $33.5 \%$ in Slovenia, and 26.0\% in the Czech Republic.

Another relationship that is usually predicted in TAM applications is the positive impact of PEU on PU. In our model, this relationship is described by hypothesis H6a, which is confirmed at a 5\% significance level in all three countries (and the magnitude does not differ statistically significantly across countries).

Four constructs and three external variables were added to the original TAM model, as shown in Figure 1. Hypothesis H1, which indicates a positive impact of PTh on PR was confirmed in all three countries, although the magnitude of the impact is different. The effect of PTh on PR was significantly stronger in Slovenia $(\beta=0.568)$ and the weakest in the Czech Republic $(\beta=0.394)$.

The same magnitude of negative impact of PR to PT (H2) was confirmed in all three countries. The negative impact of age on the BIU (H9) was not confirmed in any country.

The constructs with a positive impact on the basic components of TAM are $\mathrm{HC}$ and PT, where HC impact PU (H5), whereas PT impacts PU and BIU (H7a, H7b). Two hypotheses $(\mathrm{H} 7 \mathrm{a}, \mathrm{H} 7 \mathrm{~b})$ were confirmed in all three countries, but the magnitudes of the effects differ. Hypothesis H5 was not confirmed in the Czech Republic.

The variable PU has two significant predictors (HC and PT) that can explain between $31.4 \%$ and $47.0 \%$ of its total variance in Poland and the Czech Republic, respectively.

The positive impact of the PP external variable on $\mathrm{HC}$ was proposed with hypothesis $\mathrm{H} 4$ and confirmed in all three countries. The magnitude of the effect was highest for the Poles $(\beta=0.596)$ and lowest for the Czechs $(\beta=0.347)$. Similarly, the same positive impact of the external variable TS on PT (H3) was confirmed in all three countries. The two predictors of PT (PR and TS) explain at least $15.3 \%$ of the total variance of $\mathrm{H} 3$. 
Table 10: Testing measurement invariance of structural coefficients across countries

\begin{tabular}{|c|c|c|c|c|c|c|c|}
\hline $\begin{array}{l}\text { Structural model (SM) } \\
\text { (Model comparison) }\end{array}$ & $\begin{array}{c}\chi^{2} \\
\left(\Delta \chi^{2}\right)\end{array}$ & $d f$ & $p$ & $\begin{array}{c}C F I \\
(\triangle C F I)\end{array}$ & $\begin{array}{c}S R M R \\
(\triangle S R M R)\end{array}$ & $\begin{array}{c}\text { RMSEA } \\
(\triangle R M S E A)\end{array}$ & $\begin{array}{l}\text { RMSEA } \\
90 \% \mathrm{Cl}\end{array}$ \\
\hline $\begin{array}{l}\text { SM1 - partial strong } \\
\text { invariance }\end{array}$ & 11 & 850 & I & 854 & 127 & 083 & $0.079 ; 0.087$ \\
\hline $\begin{array}{l}\text { uctural coef- } \\
\qquad \text { (SM2) }\end{array}$ & $\begin{array}{r}2480.64 \\
(54.33)\end{array}$ & $\begin{array}{l}872 \\
(22)\end{array}$ & 0.0001 & $\begin{array}{r}0.851 \\
(-0.003) \\
\end{array}$ & $\begin{array}{r}0.131 \\
(0.004)\end{array}$ & $\begin{array}{r}0.083 \\
(0.000)\end{array}$ & $0.079 ; 0.087$ \\
\hline \multicolumn{8}{|c|}{ Constrained individual paths to be equal across groups: } \\
\hline $\begin{array}{l}\text { SM1a: PTh -> PR } \\
\text { (SM1) }\end{array}$ & $\begin{array}{r}2432.87 \\
(6.76) \\
\end{array}$ & $\begin{array}{r}852 \\
(2) \\
\end{array}$ & 0.0340 & $\begin{array}{r}0.854 \\
(0.000) \\
\end{array}$ & $\begin{array}{r}0.127 \\
(0.000) \\
\end{array}$ & $\begin{array}{r}0.083 \\
(0.000) \\
\end{array}$ & 0.07 \\
\hline $\begin{array}{l}\text { SM1b: PR -> PT } \\
\qquad(\mathrm{SM} 1)\end{array}$ & $\begin{array}{r}2427.69 \\
(1.56) \\
\end{array}$ & $\begin{array}{r}852 \\
(2) \\
\end{array}$ & 0.4589 & $\begin{array}{r}0.853 \\
(-0.001) \\
\end{array}$ & $\begin{array}{r}0.129 \\
(0.002) \\
\end{array}$ & $\begin{array}{r}0.083 \\
(0.000) \\
\end{array}$ & $0.079 ; 0.087$ \\
\hline $\begin{array}{l}\text { SM1c: TS -> PT } \\
\qquad(\text { SM1) }\end{array}$ & $\begin{array}{r}2426.60 \\
(0.49) \\
\end{array}$ & $\begin{array}{r}852 \\
(2) \\
\end{array}$ & 0.7815 & $\begin{array}{r}0.854 \\
(0.000) \\
\end{array}$ & $\begin{array}{r}0.127 \\
(0.000) \\
\end{array}$ & $\begin{array}{r}0.083 \\
(0.000) \\
\end{array}$ & 0.07 \\
\hline $\begin{array}{r}\text { SM1d: PP -> HC } \\
\qquad(\text { SM1) }\end{array}$ & $\begin{array}{r}2435.13 \\
(9.02) \\
\end{array}$ & $\begin{array}{r}852 \\
(2) \\
\end{array}$ & 0.0110 & $\begin{array}{r}0.853 \\
(-0.001) \\
\end{array}$ & $\begin{array}{r}0.128 \\
(0.001) \\
\end{array}$ & $\begin{array}{r}0.083 \\
(0.000) \\
\end{array}$ & $0.079 ; 0.087$ \\
\hline $\begin{array}{l}\text { SM1e: HC -> PU } \\
\qquad(\text { SM1) }\end{array}$ & $\begin{array}{r}2439.56 \\
(13.45)\end{array}$ & $\begin{array}{r}852 \\
(2)\end{array}$ & 0.0012 & $\begin{array}{r}0.853 \\
(-0.001)\end{array}$ & $\begin{array}{r}0.128 \\
(0.001)\end{array}$ & $\begin{array}{r}0.083 \\
(0.000)\end{array}$ & 0.08 \\
\hline $\begin{array}{l}\text { SM1f: PEU }->\text { PU } \\
\qquad(\text { SM1) }\end{array}$ & $\begin{array}{r}2426.13 \\
(0.02)\end{array}$ & $\begin{array}{r}852 \\
(2)\end{array}$ & 0.9890 & $\begin{array}{r}0.854 \\
(0.000)\end{array}$ & $\begin{array}{r}0.127 \\
(0.000)\end{array}$ & $\begin{array}{r}0.084 \\
(0.001)\end{array}$ & $0.079 ; 0.087$ \\
\hline $\begin{array}{l}\text { SM1g: PEU -> BIU } \\
\qquad(\mathrm{SM} 1)\end{array}$ & $\begin{array}{r}2426.23 \\
(13.45)\end{array}$ & $\begin{array}{r}852 \\
(2)\end{array}$ & 0.9413 & $\begin{array}{r}0.854 \\
(0.000)\end{array}$ & $\begin{array}{r}0.127 \\
(0.000)\end{array}$ & $\begin{array}{r}0.083 \\
(0.000)\end{array}$ & $0.079 ; 0.087$ \\
\hline $\begin{array}{l}\text { SM1h: PT -> PU } \\
\qquad(\text { SM1) }\end{array}$ & $\begin{array}{r}2439.66 \\
(13.55)\end{array}$ & $\begin{array}{r}852 \\
(2)\end{array}$ & 0.0011 & $\begin{array}{r}0.853 \\
(-0.001)\end{array}$ & $\begin{array}{r}0.129 \\
(0.002)\end{array}$ & $\begin{array}{r}0.083 \\
(0.000)\end{array}$ & $0.080 ; 0.087$ \\
\hline $\begin{array}{l}\text { SM1: PT -> BIU } \\
\qquad(\text { SM1) }\end{array}$ & $\begin{array}{r}2431.96 \\
(5.85)\end{array}$ & $\begin{array}{r}852 \\
(2)\end{array}$ & 0.0536 & $\begin{array}{r}0.854 \\
(0.000)\end{array}$ & $\begin{array}{r}0.129 \\
(0.002)\end{array}$ & $\begin{array}{r}0.083 \\
(0.000)\end{array}$ & $0.079 ; 0.087$ \\
\hline $\begin{array}{l}\text { SM1j: PU -> BIU } \\
\qquad(\mathrm{SM} 1)\end{array}$ & $\begin{array}{r}2427.39 \\
(1.28)\end{array}$ & $\begin{array}{r}852 \\
(2)\end{array}$ & 0.5276 & $\begin{array}{r}0.854 \\
(0.000)\end{array}$ & $\begin{array}{r}0.129 \\
(0.002)\end{array}$ & $\begin{array}{r}0.083 \\
(0.000)\end{array}$ & $0.079 ; 0.087$ \\
\hline $\begin{array}{l}\text { SM1k: Age -> BIU } \\
\qquad(\text { SM1) }\end{array}$ & $\begin{array}{r}2431.09 \\
(4.98)\end{array}$ & $\begin{array}{r}852 \\
(2)\end{array}$ & 0.0830 & $\begin{array}{r}0.854 \\
(0.000)\end{array}$ & $\begin{array}{r}0.127 \\
(0.000)\end{array}$ & $\begin{array}{r}0.083 \\
(0.000)\end{array}$ & $0.079 ; 0.087$ \\
\hline $\begin{array}{l}\text { SM3 - final model } \\
\qquad(\mathrm{SM} 1)\end{array}$ & $\begin{array}{r}2441.77 \\
(15.66)\end{array}$ & $\begin{array}{l}864 \\
(14)\end{array}$ & 0.3349 & $\begin{array}{r}0.854 \\
(0.000)\end{array}$ & $\begin{array}{r}0.128 \\
(0.001)\end{array}$ & $\begin{array}{r}0.084 \\
(0.000)\end{array}$ & 0.07 \\
\hline
\end{tabular}


Table 11: Summary of hypotheses testing for the structural model across countries

\begin{tabular}{|c|c|c|c|c|c|c|c|c|}
\hline Hypothesis \& Path & $\begin{array}{l}\text { Expected Sign } \\
\text { (Constrained } \\
\text { across groups) }\end{array}$ & Country & B & $\beta$ & $z$ & $\mathrm{p}$ & $\begin{array}{c}\text { Adjusted } \\
\mathrm{p}\end{array}$ & Confirmed? \\
\hline \multirow{2}{*}{$\mathrm{H} 1$} & \multirow[b]{3}{*}{ (No) } & $\mathrm{SI}$ & 0.769 & 0.568 & $7.631 * * *$ & 0.000 & 0.000 & Yes \\
\hline & & $\mathrm{CZ}$ & 0.441 & 0.394 & $5.670 * * *$ & 0.000 & 0.000 & Yes \\
\hline $\mathrm{PTh} \rightarrow \mathrm{PR}$ & & PO & 0.583 & 0.463 & $6.257^{* * *}$ & 0.000 & 0.000 & Yes \\
\hline \multirow[b]{3}{*}{$\mathrm{PR} \rightarrow \mathrm{PT}$} & \multirow[b]{3}{*}{ (Yes) } & $\mathrm{SI}$ & \multirow{3}{*}{-0.139} & -0.086 & \multirow{3}{*}{$-2.719 * *$} & \multirow{3}{*}{0.007} & \multirow{3}{*}{0.008} & Yes \\
\hline & & $\mathrm{CZ}$ & & -0.103 & & & & Yes \\
\hline & & $\mathrm{PO}$ & & -0.113 & & & & Yes \\
\hline \multirow[b]{3}{*}{$\mathrm{TS} \rightarrow \mathrm{PT}$} & \multirow[b]{3}{*}{ (Yes) } & $\mathrm{SI}$ & \multirow{3}{*}{0.390} & 0.387 & \multirow{3}{*}{$11.183^{* * *}$} & \multirow{3}{*}{0.000} & \multirow{3}{*}{0.000} & Yes \\
\hline & & $\mathrm{CZ}$ & & 0.422 & & & & Yes \\
\hline & & PO & & 0.375 & & & & Yes \\
\hline \multirow{3}{*}{$\mathrm{PP} \rightarrow \mathrm{HC}$} & \multirow{3}{*}{ (No) } & $\mathrm{SI}$ & 0.377 & 0.489 & $8.030 * * *$ & 0.000 & 0.000 & Yes \\
\hline & & $\mathrm{CZ}$ & 0.260 & 0.347 & $6.048^{* * *}$ & 0.000 & 0.000 & Yes \\
\hline & & $\mathrm{PO}$ & 0.505 & 0.596 & $9.480 * * *$ & 0.000 & 0.000 & Yes \\
\hline \multirow[b]{3}{*}{$\mathrm{HC} \rightarrow \mathrm{PU}$} & \multirow[b]{3}{*}{ (No) } & $\mathrm{SI}$ & -0.226 & -0.239 & $-4.053 * * *$ & 0.000 & 0.000 & Yes \\
\hline & & $\mathrm{CZ}$ & -0.038 & -0.036 & -0.713 & 0.476 & 0.476 & No \\
\hline & & PO & -0.295 & -0.264 & $-4.052 * * *$ & 0.000 & 0.000 & Yes \\
\hline \multirow{3}{*}{$\mathrm{PEU} \rightarrow \mathrm{PU}$} & \multirow[b]{3}{*}{ (Yes) } & $\mathrm{SI}$ & \multirow{3}{*}{0.480} & 0.383 & \multirow{3}{*}{$8.744 * * *$} & \multirow{3}{*}{0.000} & \multirow{3}{*}{0.000} & Yes \\
\hline & & $\mathrm{CZ}$ & & 0.332 & & & & Yes \\
\hline & & PO & & 0.374 & & & & Yes \\
\hline \multirow[b]{3}{*}{$\mathrm{PEU} \rightarrow \mathrm{BIU}$} & \multirow[b]{3}{*}{ (Yes) } & $\mathrm{SI}$ & \multirow{3}{*}{0.253} & 0.094 & & & & Yes \\
\hline & & $\mathrm{CZ}$ & & 0.074 & $2.208^{*}$ & 0.027 & 0.030 & Yes \\
\hline & & $\mathrm{PO}$ & & 0.098 & & & & Yes \\
\hline & & $\mathrm{SI}$ & 0.308 & 0.396 & $6.723 * * *$ & 0.000 & 0.000 & Yes \\
\hline $\begin{array}{c}\mathrm{H} 7 \mathrm{a} \\
\mathrm{PT} \rightarrow \mathrm{PU}\end{array}$ & & $\mathrm{CZ}$ & 0.509 & 0.599 & $11.020^{* * *}$ & 0.000 & 0.000 & Yes \\
\hline & (Yes) & $\mathrm{PO}$ & 0.264 & 0.308 & $4.803^{* * *}$ & 0.000 & 0.000 & Yes \\
\hline $\mathrm{H} 7 \mathrm{~b}$ & + & $\mathrm{SI}$ & & 0.455 & & & & Yes \\
\hline & & $\mathrm{CZ}$ & 0.755 & 0.378 & $10.908^{* * *}$ & 0.000 & 0.000 & Yes \\
\hline $\mathrm{PT} \rightarrow \mathrm{BIU}$ & (Yes) & $\mathrm{PO}$ & & 0.436 & & & & Yes \\
\hline $\mathrm{H} 8$ & + & $\mathrm{SI}$ & & 0.181 & & & & Yes \\
\hline & & $\mathrm{CZ}$ & 0.385 & 0.163 & $4.351^{* * *}$ & 0.000 & 0.000 & Yes \\
\hline $\mathrm{PU} \rightarrow \mathrm{BIU}$ & (Yes) & $\mathrm{PO}$ & & 0.191 & & & & Yes \\
\hline H9 & - & $\mathrm{SI}$ & & -0.060 & & & & No \\
\hline & & $\mathrm{CZ}$ & & -0.057 & -1.845 & 0.065 & 0.069 & No \\
\hline BIU & (Yes) & PO & -0.007 & 0.046 & & & & No \\
\hline
\end{tabular}


Table 12: Coefficients of determination $\left(R^{2}\right)$

\begin{tabular}{|c|c|c|c|}
\hline Construct & $\mathrm{SI}$ & $\mathrm{CZ}$ & $\mathrm{PO}$ \\
\hline $\mathrm{PR}$ & 0.323 & 0.155 & 0.214 \\
\hline $\mathrm{HC}$ & 0.239 & 0.120 & 0.355 \\
\hline $\mathrm{PT}$ & 0.157 & 0.189 & 0.153 \\
\hline $\mathrm{PU}$ & 0.368 & 0.470 & 0.314 \\
\hline $\mathrm{BI}$ & 0.335 & 0.260 & 0.306 \\
\hline
\end{tabular}

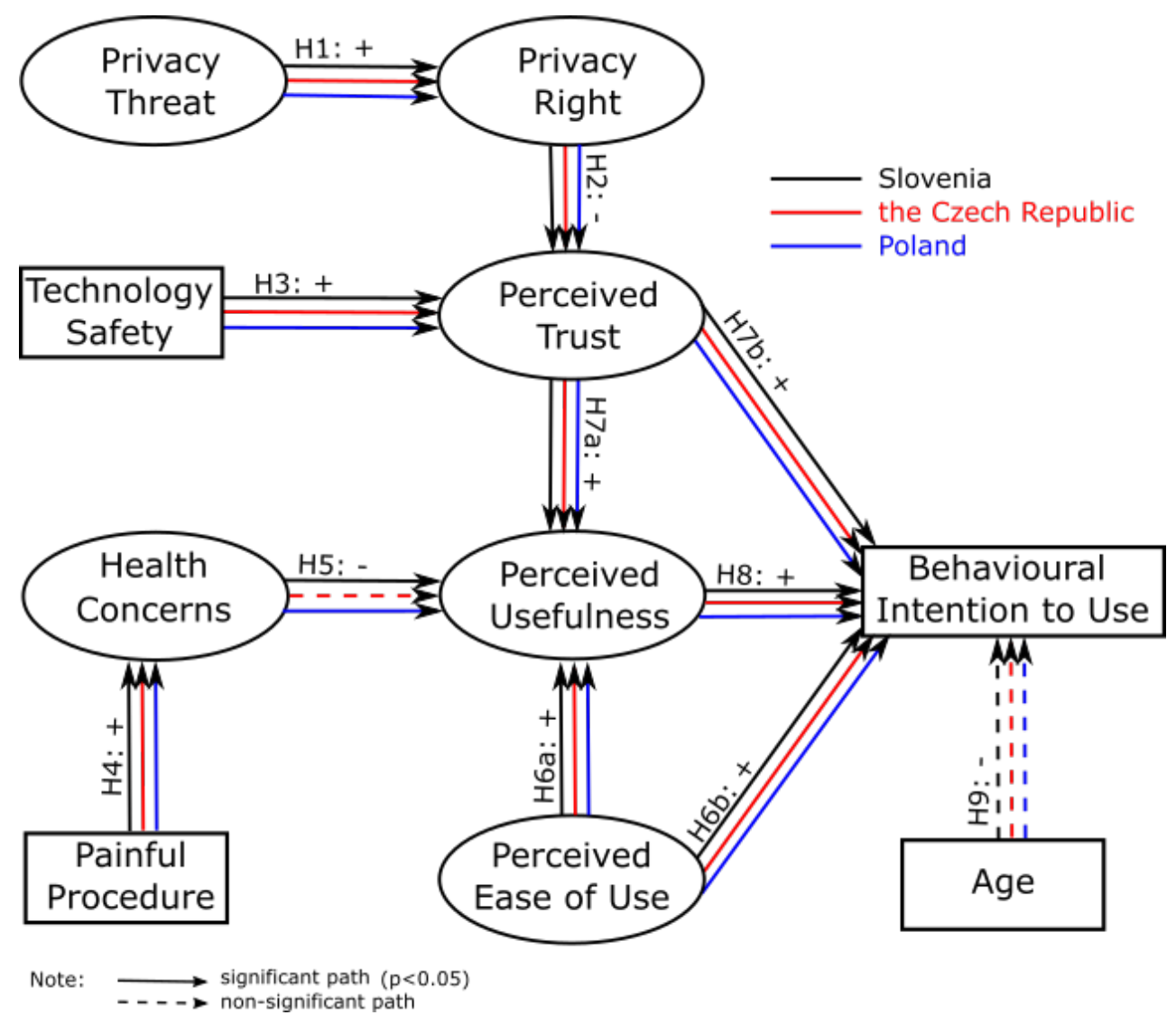

Figure 2: The final acceptance model for behavioural intention to use microchip implant

\section{Discussion and conclusions}

With today's access to information, people are becoming more and more aware of new technologies and their widespread applications. When we think about the use of new technologies, we are confronted with a variety of attitudes, from technophile to traditionalist to conservative. Despite many concerns about privacy (Rodriguez, 2019) and possible reactions to a foreign body in the human body (Albrecht, 2010), the applications of MI in healthcare are very successful (e.g. pacemakers, drug administration, prostheses). Although some people have already decided to use MI for non-therapeutic purposes (Fram et al., 2020), research on the adoption of MI by individual users, factors that influence attitudes towards MI should be investigated. Although the general attitude towards implants has changed in recent years, some health, religious or personal concerns still limit the general use of MI.

The aim of this study was to identify the drivers and barriers to the adoption of MI in the general population. It complements previous research on the adoption of MI by providing insight into the attitudes of an individual, the actual user of MI. The cross-sectional study, which was 
conducted in three European countries, showed similar attitudes towards the introduction of MIs.

In general, people would be most willing to use MI for healthcare purposes $(47.8 \%$ ), whereas, similar to Franks \& Smith (2021), willingness for other purposes was significantly lower. For example, $31.2 \%$ of respondents would be willing to use MI for identification, $20.6 \%$ for shopping and payment, and $22.8 \%$ for everyday use at home.

Perceived ease of use, usefulness, and trust were identified as the most important predictors of intention to use MIs. In addition to their influence on intention to use, perceived trust and ease of use, influence perceived usefulness. In contrast to these predictors, health concerns act as a negative predictor of perceived usefulness in two out of three countries. According to these results, the public is aware of the variety of useful applications of MI but has no confidence in research on the safety of the technology. We anticipated that due to the variety of body modifications, such as piercing, tattoos and even plastic surgery, which have become popular in recent years, the problem of pain when inserting foreign bodies will no longer be an obstacle. Nevertheless, according to the results of this study, health concerns are still anticipated by the fact that the insertion of a $\mathrm{MI}$ is a painful procedure.

Privacy right perception can be predicted by the individual's attitude towards threats to privacy. Furthermore, concerns about privacy rights act as a negative predictor of perceived trust. Given that people have become accustomed to wearable devices or smartphones and have agreed to be tracked by them in order to take advantage of their benefits, we can therefore say that this is a surprising result. In line with the lifestyle changes mentioned above, our expectation that the perceived trust is anticipated by the perception of the security of the technology of MI, was confirmed.

It is interesting to note that age is not a predictor of intention to use MIs in any of three countries studied. We expected a negative relationship between age and intention to use MIs. Table 5 shows that, the willingness to use MI is much higher when it is used for health purposes. Since older people have more health issues they might be more prone to use MIs for specific use in healthcare (e.g. MI in peacemaker) than we expected. Therefore, this specific use would need to be researched in detail. So far, we cannot confirm that older people are less likely to use new technologies.

The results show that there are barriers related to privacy issues that affect trust in MI. On the other hand, the safety of the technology has a significant positive impact on trust. Moreover, perceived trust in the technology of MI influences the decision to accept MI.

In general, we can conclude that attitudes towards the acceptance of MIs are similar in all European countries considered. The results of this research could be useful for other research areas, especially for the healthcare industry, where the use of MI could contribute the most. The bottom line is that we are not yet ready to use MI. We could use it if it would benefit our health status. There are still many health and privacy issues to be addressed in order to achieve greater adoption of this technology in our daily lives.

Although the current situation surrounding the Covid-19 pandemic has likely had a significant impact on individual perceptions of new technologies, the results of this study have made an important contribution to research on MI by providing an insight into perceptions of use from the end-user perspective. It is expected that willingness to adopt will increase as more applications of MI become available, not only in healthcare but also in daily life.

\subsection{Practical implications}

MI has the potential to become an inevitable part of our lives in the near future. Not only its applications in healthcare, but also its everyday use could significantly change our lives. The recent situation has revealed even more potential MI applications in preventing the spread of pandemics. Identifying the key factors that influence attitudes towards MI is essential for organizations aiming to promote MI and support its widespread adoption. The research shows that despite the ease of use of MI, there is still too many fears about the privacy and safety of this technology. It is therefore necessary for public authorities to ensure standards and legislation that enable the safe use of MIs.

Although several research papers show the present use of MIs by hobbyists and in certain work environments, there is still no research on the effect on the human body. Thus, before proposing a general use of MIs, research on health issues should be shifted from animals to humans so that individuals have enough information to make a reasonable decision about the use of MI.

This study also highlighted the lack of knowledge about this technology. Despite the fact that MI was introduced as a passive device that cannot be tracked from distance, the respondents were afraid of being tracked. On the other hand, most of them use mobile or wearable devices without proper security settings or even publish their location and status on social media and other platforms. It would therefore be crucial to educate the potential users about the real benefits and weaknesses of MIs before using them in a particular setting. The research also found, that people would be more willing to use MI if it would benefit their health. Thus, if MIs with health benefits (e.g. measuring blood pressure or sugar) were offered to the public, they would be more readily accepted than identification-only devices. 


\subsection{Limitations and further research}

Unlike other technologies, MIs are quite specific, so there are many arguments for and against their adoption. The variables included in the proposed model were defined based on previous research and a pilot study. We do not exclude the possibility that other external variables could influence attitudes towards the adoption of MIs (e.g. (Mohamed, 2020) including religious concerns, which we believe are not a major issue in the EMEA region where this study was conducted). The cost of implantation and use of MIs was also not considered in this study. Due to the small sample size, the Croatian subsample of this study with 146 responses (131 complete surveys) was not included in the analyses.

Although we found some similarities with studies performed on other continents (Franks \& Smith, 2021; Perakslis \& Michael, 2012), further research should include other regions or continents to obtain an overall picture of public acceptance of MI and identify the factors that influence the diversity of attitudes. In addition, other factors such as religious views, conspiracy mentality or online activities could also be considered. Particular attention should be paid to changes in attitudes due to the current extreme health problems associated with the virus COVID-19.

\section{Acknowledgements}

This research was supported by the Slovenian Research Agency; Program No. P5-0018 - Decision Support Systems in Digital Business and Prague University of Economics and Business, IG Agency, grant number F4/27/2019.

\section{Literature}

Achille, R., Perakslis, C., \& Michael, K. (2012). Ethical Issues to Consider for Microchip Implants in Humans. Ethics in Biology, Engineering and Medicine, 3, 75-86. https://doi.org/10.1615/EthicsBiologyEngMed.2013007009

Albrecht, K. (2010). Microchip-induced tumors in laboratory rodents and dogs: A review of the literature 19902006. 2010 IEEE International Symposium on Technology and Society, 337-349.

https://doi.org/10.1109/ISTAS.2010.5514622

Bansal, G., Zahedi, F. M., \& Gefen, D. (2015). Do context and personality matter? Trust and privacy concerns in disclosing private information online. Information \& Management, 53(1), 1-21. https://doi.org/10.1016/j. im.2015.08.001

Basham, R. (2014). Surveilling the Elderly: Emerging Demographic Needs and Social Implications of RFID Chip Technology Use. In M. G. Michael \& K. Michael
(Eds.), Uberveillance and the Social Implications of Microchip Implants: Emerging Technologies (pp. 169185). IGI Global. https://doi.org/10.4018/978-1-46664582-0.ch007

Beaujean, A. A. (2014). Latent variable modeling using R: A step-by-step guide. In Latent variable modeling using R: A step-by-step guide. Routledge/Taylor \& Francis Group. https://doi.org/10.4324/9781315869780

Benjamini, Y., \& Hochberg, Y. (1995). Controlling the False Discovery Rate: A Practical and Powerful Approach to Multiple Testing. Journal of the Royal Statistical Society. Series B (Methodological), 57(1), 289-300.

http://www.jstor.org/stable/2346101

Carr, N. K. (2020). As Society Strives for Reduced Contact during the Pandemic, How Can Human Microchipping Help? Villanova Law Review, 65, 46-60. https://digitalcommons.law.villanova.edu/vlr/vol65/iss6/3

Chen, F. F. (2007). Sensitivity of Goodness of Fit Indexes to Lack of Measurement Invariance. Structural Equation Modeling: A Multidisciplinary Journal, 14(3), 464504. https://doi.org/10.1080/10705510701301834

Cheung, G. W., \& Lau, R. S. (2011). A Direct Comparison Approach for Testing Measurement Invariance. Organizational Research Methods, 15(2), 167-198. https:// doi.org/10.1177/1094428111421987

Cheung, G. W., \& Rensvold, R. B. (2002). Evaluating goodness-of-fit indexes for testing measurement invariance. In Structural Equation Modeling (Vol. 9, Issue 2, pp. 233-255). Lawrence Erlbaum. https://doi.org/10.1207/S15328007SEM0902_5

Davis, F. D. (1989). Perceived Usefulness, Perceived Ease Of Use, and User Acceptance. MIS Quarterly, 13(3), 319-339. https://doi.org/10.2307/249008

Fornell, C., \& Larcker, D. F. (1981). Evaluating Structural Equation Models with Unobservable Variables and Measurement Error. Journal of Marketing Research, 18(1), 39-50. https://doi.org/10.2307/3151312

Fram, B. R., Rivlin, M., \& Beredjiklian, P. K. (2020). On Emerging Technology: What to Know When Your Patient Has a Microchip in his Hand. Journal of Hand Surgery, 45(7), 645-649. https://doi.org/10.1016/j. jhsa.2020.01.008

Franks, C., \& Smith, R. (2021). Changing perceptions of biometric technologies. In Research Report no. 20. Canberra: Australian Institute of Criminology. https:// doi.org/10.52922/rr78146

Gaffney, M., \& Gopini, G. (2020). Attitude Towards Chip Implant Devices for Individual Enhancement Purposes on Example of Estonian Population . [University of Tartu]. https://web-proxy.io/proxy/dspace.ut.ee/bitstream/handle/10062/67048/gaffney_matthew_and_ gopini_gopichand.pdf? sequence $=4 \&$ isAllowed $=\mathrm{y}$

Gauttier, S. (2019). "I" ve got you under my skin' - the role of ethical consideration in the (non-) acceptance of in- 
sideables in the workplace. Technology in Society, 56, 93-108. https://doi.org/10.1016/j.techsoc.2018.09.008

Hair, J. F., Black, W. C., Babin, B. J., \& Anderson, R. E. (2019). Multivariate Data Analysis (8th ed.). Cengage Learning.

Hu, L., \& Bentler, P. M. (1999). Cutoff criteria for fit indexes in covariance structure analysis: Conventional criteria versus new alternatives. Structural Equation Modeling, 6(1), 1-55. https://doi. org/10.1080/10705519909540118

Jorgensen, T. D., Kite, B. A., Chen, P.-Y., \& Short, S. D. (2018). Permutation randomization methods for testing measurement equivalence and detecting differential item functioning in multiple-group confirmatory factor analysis. In Psychological Methods (Vol. 23, Issue 4, pp. 708-728). American Psychological Association. https://doi.org/10.1037/met0000152

Jorgensen, T. D., S, P., Schoemann, A. M., Rosseel, Y., Miller, P., Quick, C., Garnier-Villarreal, M., Selig, J., Boulton, A., Preacher, K., Coffmann, D., Rhemtulla, M., Robitzsch, A., Enders, C., Arslan, R., Clinton, B., Panko, P., Merkle, E., Chesnut, S., ... Ben-Shachar, M. S. (2020). Useful Tools for Structural Equation Modeling. https://cran.r-project.org/web/packages/semTools/ semTools.pdf

Katz, J. E., \& Rice, R. E. (2009). Public views of mobile medical devices and services: A US national survey of consumer sentiments towards RFID healthcare technology. International Journal of Medical Informatics, 78, 104-114. https://doi.org/10.1016/j.ijmedinf.2008.06.001

Koufteros, X. A. (1999). Testing a model of pull production: a paradigm for manufacturing research using structural equation modeling. Journal of Operations Management, 17(4), 467-488. https://doi.org/10.1016/ S0272-6963(99)00002-9

Lai, H. C., Chan, H. W., \& Singh, N. P. (2016). Effects of radiation from a radiofrequency identification (RFID) microchip on human cancer cells. International Journal of Radiation Biology, 92(3), 156-161. https://doi.org/10.3109/09553002.2016.1135264

Lockton, V., \& Rosenberg, R. S. (2005). RFID: The next serious threat to privacy. Ethics and Information Technology, 7(4), 221-231. https://doi.org/10.1007/ s10676-006-0014-2

MacCallum, R. C., Browne, M. W., \& Sugawara, H. M. (1996). Power analysis and determination of sample size for covariance structure modeling. Psychological Methods, 1(2), 130-149. https://doi.org/10.1037/1082989X.1.2.130

Miceli, G. N., \& Brabaranelli, C. (2016). Structural Equations Modeling: Theory and Applications in Strategic Management. In G. B. Dagnino \& C. M. C (Eds.), Research Methods for Strategic Management (pp. 98136). Routledge/Taylor \& Francis Group. https://doi. org $/ / 10.1155 / 2012 / 263953$
Michael, K., Aloudat, A., Michael, M. G., \& Perakslis, C. (2017). You Want to do What with RFID? Perceptions of radio-frequency identification implants for employee identification in the workplace. IEEE Consumer Electronics Magazine, 6(3), 111-117. https://doi. org/10.1109/MCE.2017.2684978

Michael, K., \& Michael, M. G. (2013). The future prospects of embedded microchips in humans as unique identifiers: the risks versus the rewards. $\mathrm{Me}$ dia, Culture \& Society, 35(1), 78-86. https://doi. org/10.1177/0163443712464561

Michael, M. G., \& Michael, K. (2010). Toward a State of Überveillance [Special Section Introduction]. IEEE Technology and Society Magazine, 29(2), 9-16. https:// doi.org/10.1109/MTS.2010.937024

Mohamed, M. A. (2020). Modeling of Subcutaneous Implantable Microchip Intention of Use. In T. Ahram, W. Karwowski, A. Vergnano, F. Leali, \& R. Taiar (Eds.), Intelligent Human Systems Integration 2020 (pp. 842847). Springer International Publishing. https://doi. org//10.1007/978-3-030-39512-4 128

Perakslis, C., \& Michael, K. (2012). Indian Millennials: Are microchip implants a more secure technology for identification and access control? Proceedings of the 2012 IEEE Conference on Technology and Society in Asia, T and SA 2012, 2012, 1-9. https://doi. org/10.1109/TSAsia.2012.6397977

Perakslis, C., Michael, K., Michael, M. G., \& Gable, R. (2014). Perceived Barriers for Implanting Microchips in Humans : A Transnational Study. In Norbert Wiener in the 21st Century (21CW). https://doi.org/10.1109/ NORBERT.2014.6893929

Putnick, D. L., \& Bornstein, M. H. (2016). Measurement invariance conventions and reporting: The state of the art and future directions for psychological research. Developmental Review, 41, 71-90. https://doi.org/ https://doi.org/10.1016/j.dr.2016.06.004

Rodriguez, D. A. (2019). Chipping in at work: Privacy concerns related to the use of body microchip ("RFID") implants in the employer-employee context. Iowa Law Review, 104(3), 1581-1611. https://ilr.law.uiowa.edu/ assets/Uploads/ILR-104-3-Rodriguez.pdf

Rosseel, Y. (2014). The lavaan tutorial. In The lavaan tutorial. http://lavaan.ugent.be/tutorial/tutorial.pdf

Rotter, P., Daskala, B., \& Compano, R. (2008). RFID implants: Opportunities and and challenges for identifying people. IEEE Technology and Society Magazine, 27(2), 24-32. https://doi.org/10.1109/mts.2008.924862

Sarwar, N., Khan, F. N., Ali, A., Rafique, H., Hussain, I., \& Irshad, A. (2019). Microchip with Advance Human Monitoring Technique and RFTS. In I. S. Bajwa, F. Kamareddine, \& A. Costa (Eds.), Intelligent Technologies and Applications (pp. 560-570). Springer Singapore. https://doi.org//10.1007/978-981-13-6052-7 48

Schumacker, R. E., \& Lomax, R. G. (2010). A beginner's guide to structural equation modeling, 3rd ed. In $A$ be- 
ginner's guide to structural equation modeling, 3rd ed. Routledge/Taylor \& Francis Group.

Smith, C. (2008). Human microchip implantation. Journal of Technology Management and Innovation, 3(3), 151-156. https://doi.org/10.4067/S071827242008000100015

Teo, T., \& Zhou, M. (2014). Explaining the intention to use technology among university students: a structural equation modeling approach. Journal of Computing in Higher Education, 26(2), 124-142. https://doi. org/10.1007/s12528-014-9080-3

Turner, W. (2020). Chipping Away at Workplace Privacy: The Implantation of RFID Microchips and Erosion of Employee Privacy. Washington University Journal of Law \& Policy, 61, 275-298.

https://openscholarship.wustl.edu/law_journal_law_ policy/vol61/iss 1/18/

Virkki, J., Wei, Z., Liu, A., Ukkonen, L., \& Björninen, T. (2017). Wearable passive E-textile UHF RFID tag based on a slotted patch antenna with sewn ground and microchip interconnections. International Journal of Antennas and Propagation, 2017, 27-29. https://doi. org $/ 10.1155 / 2017 / 3476017$

Werber, B., Baggia, A., \& Žnidaršič, A. (2018). Factors Affecting the Intentions to Use RFID Subcutaneous Microchip Implants for Healthcare Purposes. Organizacija, 5l(2), 121-133. https://doi.org/10.2478/orga2018-0010

Anja Žnidaršič is an Associate Professor of Quantitative Methods at the Faculty of Organizational Sciences, University of Maribor, Slovenia. Her main research interests are social network analysis, microenterprises, information-communication technology, students' performance in methodological courses, and technology adoption.

Alenka Baggia is an Assistant Professor of Information Systems at the Faculty of Organizational Sciences, University of Maribor. Her main research interests are digital literacy, technology acceptance, green information systems, and software quality.

Antonín Pavlíček is Senior Assistant at Department of Informatics and Analytical Methods at University College of Business in Prague. His main research interests include new media, social media, information management and information security.

Jakub Fischer is the Dean of the Faculty of Informatics and Statistics of the Prague University of Economics and Business. He focuses his research on the field of social and economic statistics and national accounting.

Maciej Rostański is an Assistant Professor at the Computer Science Faculty of WSB Academy in Dąbrowa Górnicza, Poland. His main research interests include cloud computing, cyber security and Internet of Things.

Borut Werber is an Assistant Professor of Information Systems at the Faculty of Organizational Sciences, University of Maribor, Slovenia. His main research interests are micro-enterprises, informationcommunication technology, and novel technologies. 